\title{
A simple model of Cs-137 profile to estimate soil redistribution in cultivated stony soils
}

J. Soto ${ }^{1}$ and A. Navas ${ }^{2}$

${ }^{1}$ Departamento de Ciencias Médicas y Quirúrgicas, Universidad de Cantabria, Avenida Cardenal Herrera Oria s/n, 39011 Santander, Spain. sotoj@unican.es

${ }^{2}$ Departament of Soil and Water. Estación Experimental de Aula Dei, CSIC. Apartado 202, 50080 Zaragoza, Spain. anavas@eead.csic.es

\section{Abstract}

A main issue in soil erosion studies is to calibrate ${ }^{137} \mathrm{Cs}$ data to provide satisfactory estimates of erosion and deposition rates. The cultivation on steep slopes in some areas of the South Central Pyrenees results in serious affections to soils due to water erosion that mobilizes soil particles down slope. In the region, the intensive soil use including deforestation, overgrazing and extensive agriculture during the last centuries together with some characteristics of the soils such as poor development, thin soil profiles and high stone contents make them prone to erosion. A model based on ${ }^{137} \mathrm{Cs}$ profile is proposed to calculate erosion or sedimentation rates in these cultivated soils. The model uses parameters such as the volume of the fine fraction of the soils and the depth of cultivation calculated from the values obtained just from the soil sampling. Using a computer program the annual deposit of ${ }^{137} \mathrm{Cs}$ is simulated for an erosion or deposition rate of soil. To test the model, ${ }^{137} \mathrm{Cs}$ profiles of cultivated soils were collected at sampling sites located on temperate slopes in the Sierra de la Carrodilla (South 
Pyrenees) and experimental results were simulated with the model. The simulation results of the model were consistent with the experimental results of ${ }^{137} \mathrm{Cs}$ concentrations and inventories. The model offers a potential to describe the soil redistribution in stony soils and estimates of erosion and deposition rates can be calculated easily for a range of the most common soils found in Mediterranean environments.

Key words: fallout ${ }^{137} \mathrm{Cs}$; modelling; cultivated stony soils; erosion and deposition rates; mountain slopes; Mediterranean.

\section{Introduction}

Fallout ${ }^{137} \mathrm{Cs}$ has proved to be a reliable method for quantifying soil losses. The radiometric technique has been successfully applied in the last three decades to assess the erosion produced by runoff and rills in a variety of environments around the world (e.g. Ritchie and McHenry, 1990; Walling and Quine, 1990; Zhang et al.,1990; Wallbrink and Murray, 1996).

The shallow soil profiles together with high stoniness are main features of degradation in soils on cultivated mountain slopes. In temperate and semiarid mountain regions, a high percentage of soils is affected by erosion. As much as $40 \%$ of the Spanish territory suffers important soil losses. The severity of this problem obliges to apply sound methodologies to quantify soil losses. Within the Mediterranean environment, the assessment of soil erosion by ${ }^{137} \mathrm{Cs}$ is producing good results since the 1990's (Navas and Walling, 1992) to more recent studies (Schoorl et al., 2004; Navas et al., 2005 c, 2007). 
The questions arise on the application of models to calibrate ${ }^{137} \mathrm{Cs}$ data (Quine, 1989; Owens and Walling, 1998). It is well known in the literature (Walling and He, 1998) that application of different models produce different estimations. In the case of Mediterranean stony soils, Navas and Walling (1992) highlighted that high stone contents affected the estimation of erosion rates because similar ${ }^{137} \mathrm{Cs}$ profiles exhibited very diverse total inventories. This fact was a main concern as to develop a model for rangeland soils by Soto and Navas (2004) that accounted the stone content to relate the ${ }^{137} \mathrm{Cs}$ inventories with the rates of soil redistribution.

Around the world they are abundance of cultivated mountain soils and the increasing anthropogenic pressure is rapidly transforming rangeland in farmland, hence soil erosion is expected to worsen in the future. Under the perspectives of climatic change that will especially affect the Mediterranean regions the predictions are longest droughts together with more extreme rainfall events (Meehl et al., 2005). This climatic pattern will aggravate the effect of suppressing the vegetation cover for cultivation as it is currently occurring on slopes of the Rif Range in Morocco (Sadiki et al., 2007).

Research carried out in the semiarid area of Las Bardenas (NE, Spain) showed that erosion rates on cultivated land were five times higher than on uncultivated land (Quine et al., 1994). In such semiarid regions of Spain and North Africa the intense erosive dynamics especially threats the cultivated soils (Navas et al., 1997; Faleh et al., 2005). On mountain slopes, soils are generally shallow and the content of stones is generally high reaching as much as $50 \%$. In some highly eroded areas, water and tillage erosion transport soil particles down-slope and after loosing the mineral components as well as nutrients only stone pavements remain (Navas et al., 1997; Poesen et al., 1997).

In the present work and because the highest risk of loosing fertile soil occurs on agricultural lands, our objective is to develop a simple model of ${ }^{137} \mathrm{Cs}$ profile for 
cultivated stony soils. In such manner, the model will relate the depth distribution of ${ }^{137}$ Cs with erosion or deposition rates at the study sites. The proposed model is tested to estimate the soil redistribution on selected cultivated soils in an area of the SouthPyrenees. The selected soils are under rainfed cultivation and annual rainfall in the area is around $550 \mathrm{~mm}$. Therefore, estimation of soil erosion rates may considered as representative of productive agroecosystems that can be at danger under the perspectives of climate change. The information on accurate rates of soil redistribution is of interest as a first step to preserve the soil resource in fragile environments.

\section{The ${ }^{137}$ Cs model}

The proposed model has just one compartment that extends from the soil surface to a depth "H", which is the cultivation depth. In the compartment there are two types of soil fractions, the fine material whose grain sizes are less than $2 \mathrm{~mm}$, and the coarse fraction of more than $2 \mathrm{~mm}$. Each one of these soil fractions are characterized by its own mass, volume and density. Due to the great difference between the specific surfaces of the two fractions, the ${ }^{137} \mathrm{Cs}$ is only contained in the fine fraction (Livens and Rimmer, 1988). This fact defines the volume fraction for fixing ${ }^{137} \mathrm{Cs}$, Vf, as the relation between the volume occupied by the fine fraction and the total volume of the compartment.

The proposed model assumes a temporary evolution of the ${ }^{137} \mathrm{Cs}$ concentration in the compartment. This temporary evolution begins with a total inventory equal to zero during the years before 1954, increasing from this year in a quantity equal to the corresponding atmospheric deposit. This quantity has a known temporary evolution, (quoted in Walling and Quine, 1990). The ${ }^{137}$ Cs activity deposited is homogeneously distributed in the compartment within its Vf. Thus, if $\mathrm{C}(\mathrm{t})$ is the total inventory in a 
given $\mathrm{t}$ moment, $\mathrm{C}(\mathrm{t}-1)$ is the total inventory in the previous moment and $\mathrm{D}(\mathrm{t})$ is the atmospheric deposit in that interval. Then, the following equation is formulated,

$$
C(t)=C(t-1)+D(t)
$$

Similarly, the ${ }^{137}$ Cs activity by unit of volume, a ( $\left.t\right)$, increases as follows

$$
\mathbf{a}(\mathbf{t})=\mathbf{a}(\mathbf{t}-\mathbf{1})+(\mathbf{D}(\mathbf{t}) / \mathbf{H} * \mathbf{V f})
$$

In addition, the evolution of the deposit of atmospheric ${ }^{137} \mathrm{Cs}$, i.e. the existing isotope activity in the compartment decreases due to the loss of soil particles with a specific concentration, which is produced by soil erosion. If we assign $\mathrm{E}$ to the thickness of the soil layer that is lost per unit of time, the total inventory of ${ }^{137} \mathrm{Cs}$ in the compartment will decrease as follows

$$
\mathbf{C}(\mathbf{t})=\mathbf{C}(\mathbf{t}-\mathbf{1})(\mathbf{1}-(\mathbf{E} / \mathbf{H} * \mathbf{V f}))
$$

Similar to the procedure undertaken to estimate the decreases of ${ }^{137} \mathrm{Cs}$ inventories caused by erosion it is possible to estimate the increases of total ${ }^{137} \mathrm{Cs}$ activity in the compartment for the sites where there is soil deposition. Even though, in this case the increase of ${ }^{137} \mathrm{Cs}$ activity depends on the concentration of the radioisotope already existing in the material deposited at a certain site. This concentration will be different in function of the origin of the soil material, i.e. if it is a stable, eroded or aggraded soil. To solve this problem an approach can be to suppose that the deposited material at a site has the same ${ }^{137} \mathrm{Cs}$ concentration than the nearby sites. However, when the distances 
between sampling sites are great then the deposited material from other points do not bring this concentration value.

In our model, the incorporated material is supposed to come from a short distance and therefore has the same ${ }^{137} \mathrm{Cs}$ concentration that the already existing in the point. With this supposition and assigning $\mathrm{F}$ to the material deposited per unit of time, the ${ }^{137} \mathrm{Cs}$ inventory will increase in the way

$$
\mathbf{C}(\mathbf{t})=\mathbf{C}(\mathbf{t}-\mathbf{1})(\mathbf{1}+(\mathbf{F} / \mathbf{H} * \mathbf{V f}))
$$

In any of the former cases, the model also has a term that describes the decrease of the ${ }^{137} \mathrm{Cs}$ activity along with time due to its radioactive decay.

With these characteristics, the model was implemented in a simple program written in BASIC language. In the program, the values of the deposit of ${ }^{137} \mathrm{Cs}$ from the atmosphere are also included. The values of the annual fallout of ${ }^{137} \mathrm{Cs}$ on a site depend on physiographic and climatic factors like latitude and annual rainfall. The ${ }^{137} \mathrm{Cs}$ deposition on the surface is known in detail in certain parts of the world (e.g. Blagoeva \& Zikowsky, 1995). At medium latitudes in the Northern Hemisphere, the deposition shows a similar temporal evolution for ${ }^{90} \mathrm{Sr}$ and ${ }^{137} \mathrm{Cs}$ (Ritchie \& McHenry, 1990). It can, therefore, be a fair approximation to assume that the same evolution should be adjusted to the existing points of reference, although the absolute values were according local climatic characteristics. According to that reason we have chosen a temporal evolution for ${ }^{137} \mathrm{Cs}$ deposition described by Ritchie and McHenry (1990), modifying the absolute values by a multiplicative factor in order to adjust the predicted total inventory from the point of measurement. This factor is such that the corrected values bring total 
inventories at the reference sites, where there is not deposit or erosion, like those measured at the experimental reference sites.

The functioning of the programme considers monthly temporal intervals. In each of these intervals the ${ }^{137} \mathrm{Cs}$ activity develops according to the three already mentioned processes. These processes are the atmospheric deposition with distribution in the compartment, ground erosion or deposit and the radioactive decay that are included in the program according to the reported equations. The program calculates the total charge and the concentration of ${ }^{137}$ Cs existing in the compartment from the year 1954 to the year of sampling collection.

\section{Material and methods}

\subsection{Experimental profiles}

In order to check that the results obtained with the model serve to describe experimental profiles, several soil profiles were collected along slopes of the Carrodilla Range (Huesca province, NE Spain). This study area is representative of the physiography, vegetation and soil types existing in a large sector of the South Pyrenean Ranges (The External Ranges). In the area there is an abrupt landscape and altitudes range between 676 and $896 \mathrm{~m}$. The annual rainfall is around $550 \mathrm{~mm}$. The materials are limestones (Muschhelkalk age), clay and gypsum (Keuper age) and colluvial-alluvial materials of Quaternary age. On steep calcareous slopes the soils are mainly shallow Leptosols, Regosols and Calcisols. On Keuper materials are Gypsisols whilst Calcisols and Gleysols are developed on Quaternary materials. The main properties of soils at the experimental sites are summarized in Table 1.

The sampling collection was made on three transects along the slopes of the study area (Quine et al. 1994; Navas et al. 2005b). The slopes are South, East and West 
orientated. Of the total selected sites on the slope transects, 16 were cultivated soils. Soil cores were collected by using an automatic core driller and sectioned at $5 \mathrm{~cm}$ depth intervals (Navas et al., 2002a). In general, the average sampling depth above the rock outcrop was 40-45 $\mathrm{cm}$. Samples were air-dried, ground and passed through a $2 \mathrm{~mm}$ sieve. The weights and densities of the two fractions $<2$ and $>2 \mathrm{~mm}$ (fine and coarse material) were determined. Once homogenized, $50 \mathrm{~g}$ of the $<2 \mathrm{~mm}$ fraction were taken to standardize geometry plastic containers for measuring ${ }^{137} \mathrm{Cs}$ concentration.

The ${ }^{137}$ Cs activities were measured using a high resolution, low background, coaxial gamma-ray detector of hyperpure germanium coupled to an amplifier and multichannel analyser (Quindós et al. 1994; Navas et al. 2002b; Remondo et al. 2005). The efficiency of the detector was $20 \%$, with $1.86 \mathrm{keV}$ resolution (shielded to reduce background) and was calibrated using standard samples in the same geometry as the measured samples. Gamma emissions of ${ }^{137} \mathrm{Cs}\left(662 \mathrm{keV}\right.$ line in $\mathrm{mBq} \mathrm{g}^{-1}$ air-dry soil $)$ were measured for 267 samples. Counting time was $30000 \mathrm{~s}$ and the analytical precision of the measurements was approximately $\pm 10 \%$.

\section{Applying the model}

The ${ }^{137} \mathrm{Cs}$ inventories $\left(\mathrm{mBq} \mathrm{cm}{ }^{-2}\right)$ for the surface area at each sampling site are calculated from the ${ }^{137} \mathrm{Cs}$ concentrations measured in the samples in $\mathrm{mBq} \mathrm{g}^{-1}$ taken into account the surface area of the soil sampler and the mass of the fine fraction. The ${ }^{137} \mathrm{Cs}$ concentrations are estimated in the soil profile intervals considering both the density of the fine fraction $(\leq 2 \mathrm{~mm})$ and its volume fraction $(\mathrm{Vf})$. The values of $\mathrm{Vf}$ for the soil samples of this study range between 0.54 and 0.97 and the density values of the fine fraction are between 0.68 and $1.6 \mathrm{~g} \mathrm{~cm}^{-3}$. 
A similar procedure was undertaken at stable sites that were not affected by erosion or deposition (Figure 1). These sites were used as reference inventories for the area and the inventory value was $157 \pm 8 \mathrm{mBq} \mathrm{cm}^{-2}$.

The soil depth distribution of the ${ }^{137} \mathrm{Cs}$ inventories allows discriminate between cultivated and uncultivated soils. The latter are characterized by rapidly decreasing inventories with depth and the radioisotope is found until $25-30 \mathrm{~cm}$ deep (Navas and Walling, 1992). In contrast, the cultivated soils present very homogeneous ${ }^{137}$ Cs profiles until the depth of cultivation, due to the mixing of soil by tillage. In general, below the tillage depth ${ }^{137} \mathrm{Cs}$ inventories are almost zero. In cultivated soils the ${ }^{137} \mathrm{Cs}$ profiles are in general longer and the depth to which ${ }^{137} \mathrm{Cs}$ is detected exceeds $10-15 \mathrm{~cm}$ that in uncultivated soils.

Along the transect slopes of cultivated soils, a total of 11 sites had inventories lower than the reference inventory for the study area, indicating that they are erosion sites. Other 5 sites had inventories higher than the reference for the area and therefore correspond to deposition sites (Figure 1). The profiles presented in Figure 1 are a selection of profile types found along the slopes of the study area of Carrodilla. Stable sites are those where no erosion or deposition occurs, these sites are used as references for the area they are almost flat, covered with natural vegetation and remain unaltered. Deposition profiles are those where material coming from other sites is accumulated.

The 11 eroding sites have total inventories between 32.2 and $128.9 \mathrm{mBq} \mathrm{cm}^{-2}$. Their depth profiles are constant until the depth of cultivation which is between 15 and $40 \mathrm{~cm}$. Below this depth, ${ }^{137} \mathrm{Cs}$ is almost un existing. The depth distribution of the ${ }^{137} \mathrm{Cs}$ concentration follows a similar pattern and their average values range between 1.4 and $5.5 \mathrm{mBq} \mathrm{g}^{-1}$ (Table 2). 
The proposed model was used to estimate the erosion rates in these eroding sites. For each site, the model runs with the $\mathrm{H}$ value (the depth of cultivation) which is clearly marked by the depth distribution of the radioisotope. In addition, the values of $\mathrm{Vf}$ (volume fraction) and the density of the fine fraction are also introduced in the model. The values of Vf range between 0.54 and 0.92 and the density of the fine fraction varies between 0.68 and $1.5 \mathrm{~g} \mathrm{~cm}^{-3}$. With the referred values, several values of $\mathrm{E}$, the erosion rate, in $\mathrm{cm} / \mathrm{month}$, were tested until the value of $\mathrm{E}$ that agrees with the total inventory at the site is found. Then, the average concentration in the soil profile coincides with the measured value at the site. From the estimated value, the annual erosion rate is calculated in Mg per ha using the value of the density of the fine fraction.

The values of the erosion rates calculated with the model range between $14.6 \mathrm{Mg}$ $\mathrm{ha}^{-1} \mathrm{yr}^{-1}$ for a ${ }^{137} \mathrm{Cs}$ inventory of $83.0 \mathrm{mBq} \mathrm{cm}^{-2}$ and $69.3 \mathrm{Mg} \mathrm{ha}^{-1} \mathrm{yr}^{-1}$ for a ${ }^{137} \mathrm{Cs}$ inventory of $32.2 \mathrm{mBq} \mathrm{cm}^{-2}$ (Table 2). It is important to point out the clear influence of the cultivation depth $(\mathrm{H})$ and the values of the volume fraction (Vf) on the final estimation of erosion rates. The mentioned factors, $\mathrm{H}$ and the stoniness associated to the volume of fine fraction that can fix the radioisotope (Vf) are the reason by why the usual direct relation between the percentage of ${ }^{137} \mathrm{Cs}$ lost and that of soil lost is not maintained as in other models. Figure 2 exhibit both the experimental and the modelled ${ }^{137} \mathrm{Cs}$ profiles for various eroding sites. The profiles exhibit a quite homogeneous distribution within the depth of tillage that varies between $20 \mathrm{~cm}$ in steep slope sites until $40 \mathrm{~cm}$ for gentle slope sites. In general, below the depth of cultivation ${ }^{137} \mathrm{Cs}$ was not found.

In the five aggrading sites a gain of soil particles occurs. The values of ${ }^{137} \mathrm{Cs}$ inventories range between 158.8 and $216.7 \mathrm{mBq} \mathrm{cm}^{-2}$. The ${ }^{137} \mathrm{Cs}$ depth distribution is also quite constant and the radiosotope is found until a depth of $40 \mathrm{~cm}$. The ${ }^{137} \mathrm{Cs}$ 
concentrations vary less than in the eroding profiles and range between 3.8 and $4.8 \mathrm{mBq}$ $\mathrm{g}^{-1}$ (Table 3).

Similar to what it was done for the eroding profiles, the values of $\mathrm{H}$ obtained from the ${ }^{137} \mathrm{Cs}$ depth distribution in the experimental profiles, Vf and density of the fine fractions are entered to run the model. The values of Vf range between 0.81 and 0.97 and the density of the fine fraction varies between 1.2 and $1.6 \mathrm{~g} \mathrm{~cm}^{-3}$. With these two factors, different values of $\mathrm{F}$, which is the monthly aggrading rate, were tested until the total inventory for the site coincides with the experimental value. Then the annual deposition rate is quantified in $\mathrm{Mg}$ per ha $\left(\mathrm{Mg} \mathrm{ha}^{-1} \mathrm{yr}^{-1}\right)$ using the density of the fine fraction.

For the study sites, the deposition rate varied between $0.9 \mathrm{Mg} \mathrm{ha}^{-1} \mathrm{yr}^{-1}$ for a ${ }^{137} \mathrm{Cs}$ inventory of $158.8 \mathrm{mBq} \mathrm{cm}^{-2}$ and $33.4 \mathrm{Mg} \mathrm{ha}^{-1} \mathrm{yr}^{-1}$ for a ${ }^{137} \mathrm{Cs}$ inventory of $216.7 \mathrm{mBq}$ $\mathrm{cm}^{-2}$ (Table 3). As in the case of the eroding profiles, the important effect of both the depth of tillage " $\mathrm{H}$ " and the stoniness content that determines the volume of fine soil on which ${ }^{137} \mathrm{Cs}$ is fixed are the reason of the lack of proportionality between the ${ }^{137} \mathrm{Cs}$ gain and the soil deposited at a site. Figure 3 presents some examples of the ${ }^{137} \mathrm{Cs}$ depth profiles found experimentally and modelled.

\section{Discussion}

It is of interest to compare our model with other models that are currently used. Among the models that relate the ${ }^{137} \mathrm{Cs}$ loss with that of soil in cultivated lands are the proportional models, including the gravimetric approach and the mass balance models.

The proportional models assume a linear relationship between the decrease in the

${ }^{137} \mathrm{Cs}$ inventory in comparison with the reference for the area and the erosion rate. This relationship is used in its more simple way by de Jong et al. (1983) and Kachanosky 
(1987), and it is slightly modified in Martz and de Jong (1987). Chappell et al. (1988) also follow this approach although they introduce an additional factor that provides smaller erosion rates than the calculated ones.

In the gravimetric approach by Brown et al. (1981) in Lowrance et al. (1988) and Fredericks and Perrens (1988), these authors apply an approach slightly different that uses the average concentration and not the depth of cultivation. The linear relationship assumed in the proportional methods does not consider the fact that the ${ }^{137} \mathrm{Cs}$ lost depends on the concentration of the radioisotope in each moment. Consequently, the same erosion rate produces higher loss of ${ }^{137} \mathrm{Cs}$ in time intervals in which the concentration of ${ }^{137} \mathrm{Cs}$ is higher than when it is reduced by erosion of the soil.

In order to take into account the fact of the different loss of ${ }^{137} \mathrm{Cs}$ with time, the mass balance models were proposed. These models calculate the temporal evolution of the ${ }^{137} \mathrm{Cs}$ inventory. The loss of ${ }^{137} \mathrm{Cs}$ due to erosion is differently expressed in the various models. In Kachanosky and de Jong (1984) this loss is approached as the product of the erosion rate by the ${ }^{137} \mathrm{Cs}$ concentration in spite that the latter is not calculated. Zhang et al. (1999) relate the thickness of the soil layer that is lost annually with the thickness of the tillage layer. Kachanosky (1993) establishes a relationship between the erosion rate and the massic thickness of the soil. Moreover, Walling and He (1999) introduce a term that takes into account the selectivity of the ${ }^{137}$ Cs transport associated to the size of the soil articles.

In the model proposed in this work the erosion rate is expressed as a product of the thickness of soil lost by the ${ }^{137} \mathrm{Cs}$ concentration, which is estimated for each time interval. To this respect is a mass balance model that takes advantage of the knowledge of the concentration of the radioisotope. In addition, the model acquires reliability 
because it also uses the depth of cultivation that is previously known by the depth distribution of the radioisotope.

It is of interest to highlight the use of the depth of cultivation in our model. In most models this parameter is a constant value derived from the general knowledge of the tillage practices in the study areas. This is reasonable when the areas under study have homogeneous tillage practices maintained through the time. However in many Mediterranean regions, heterogeneity of both terrain and tillage practices is common. Furthermore, as in our study area the depth of cultivation varies depending on the steepness of slopes, thus deeper tillage practices are undertaken in gentle slope fields.

Other important factors of variation are the changes that were introduced in land management. Thus, tillage depth was in general $40 \mathrm{~cm}$ but more recently minimum tillage practices following the establishment of better management practices has reduced considerably the depth of cultivation that varies from strictly shallow tillage $(5 \mathrm{~cm})$ till $20 \mathrm{~cm}$. Under these changing conditions and due to the main role of the depth of cultivation in the models, it is necessary to use the experimental ${ }^{137} \mathrm{Cs}$ depth profiles measured at sampling sites.

Together with $\mathrm{H}$, another very important factor is the volume that the fine fraction $(<2 \mathrm{~mm})$ occupies in relation to the total volume of the soil sampled. In Mediterranean soils as these under study, the stoniness is a main soil property that notably influences the erosion process (Govers et al., 2006). Therefore, it is necessary to include a parameter for describing the stoniness because the stone content affects greatly the distribution of ${ }^{137} \mathrm{Cs}$ within the soil depth profile, and as consequence can modify the rates of erosion quantified by the different models.

Erosion and deposition rates estimated with our model compare well with estimates obtained by using other mass balance models based on fallout ${ }^{137}$ Cs. Thus in 
the nearby area of Bardenas (Spain) estimates of soil redistribution by Quine et al., (1994) also vary largely ( $>+5$ to $>-40 \mathrm{Mg} \mathrm{ha}^{-1} \mathrm{yr}^{-1}$ ). Also similar values of soil losses were found in the Rift (Morocco) by Sadiki et al., (2007) that quantified erosion rates ranging between 5 and $49 \mathrm{Mg} \mathrm{ha}^{-1} \mathrm{yr}^{-1}$ by applying a mass balance model by Zhang et al., (1990) and (Walling and He, 1999).

Previous experience in similar environments (Navas and Walling, 1992; Navas et al,. 2007) demonstrated that influence of stoniness is very important. Sites that had similar total inventories presented different ${ }^{137} \mathrm{Cs}$ depth distributions. The inclusion of the volume fraction to determine that part on which the radioisotope is fixed can help to overcome this problem. This is of great importance for Mediterranean soils that are in general very stony. This character also has an effect on the most suitable interval for sectioning the soil profiles. To obtain unaltered subsamples, the sectioning of stony soils has to be done at $5 \mathrm{~cm}$ depth intervals as smaller thickness may produce soil disturbance when extracting the stones between intervals (Navas et al., 2005a).

\section{Conclusions}

To estimate the soil redistribution based on fallout ${ }^{137} \mathrm{Cs}$ measurements the proposed model has as main characteristic that it runs with parameters obtained simply from experimental measurements in soil profiles. It is a simple model that uses generic data of ${ }^{137}$ Cs fallout modified by a local factor of deposition that agrees with data of the reference deposit measured. The model uses weights, volumes and densities calculated from the soil samples. The depth of cultivation is also a known parameter obtained from the depth distribution of ${ }^{137} \mathrm{Cs}$ at a site.

Erosion and deposition rates obtained with our model compare well with estimates in other areas nearby as in las Bardenas (Spain) and in the Rift (Morocco) 
where other mass balance models based on fallout ${ }^{137} \mathrm{Cs}$ were applied. Future research concerning the estimation of ${ }^{137} \mathrm{Cs}$ inventory of the material deposited at a measured site will improve the model. Although this is general limitation in similar models, is solved by applying the models on transects where the inventory in the point at the upper location of the measured site is known.

The good adjustment between the data measured and modelled, as well as its easiness of use represent an advantage for the quantification of erosion and deposition rates in cultivated stony soils. In Mediterranean environments and other mountain stony soils are abundant. The use of this model in mountain agroecosystems will serve for quantifying soil losses, which is a first issue to promote effective soil conservation and management practices.

\section{Acknowledgements}

This work was funded by the bilateral projects 2004MA-1005 and 18304-RM from the Agencia de Cooperación Interuniversitaria and the CICYT projects RADIERO (REN2002-02702/GLO) and REM (CGL2005-02009/BTE).

\section{References}

Blagoeva, R., Zikovsky, L., 1995. Geographic and vertical distribution of Cs-137 in soils in Canada. J. Environ. Radioactiv. 27, 269-274.

Brown, R.B., Kling, G.F., Cutshall, N.H., 1981. Agricultural erosion indicated by Cs137 redistribution: estimate of erosion rates. Soil Sci. Soc. Am. J. 45, 1191-1197.

Chappell, A., Warren, A., Oliver, M,A., Charlton, M., 1998. The utility of 137Cs for measuring soil redistribution rates in south-west Niger. Geoderma 81, 313-337. 
de Jong, E., Begg, C.B.M., Kachanosky, G., 1983. Estimates of soil erosion and deposition for some Saskatchewan soils. Can. J. Soil Sci. 3, 607-617.

Faleh, A., Navas, A., Sadiki., A., 2005. Erosion and dam siltation in a Rif catchment (Morocco). In: Horowitz, A.J., Walling, D.E. (Eds.), Sediment Budgets 2. IAHS Publi. 292, 58-64.

Fredericks, D.J., Perrens, S.J., 1988. Estimating erosion using caesium-137: II Estimating rates of soil loss. IAHS Publi. 174, 225-231.

Govers, G., Van Oost, K., Poesen, J. 2006. Responses of a semi-arid landscape to human disturbance: simulation study of the interaction between rock fragment erosion and land use change.Geoderma 133, 19-31

Kachanosky, R,G., De Jong, E., 1984. Predicting the temporal relationship between soil cesium-137 and erosion rate. J. Environ. Qual. 13, 301-304.

Kachanosky, R.G., 1987. Comparison of measured soil 137-cesium losses and erosion rates. Can. J. Soil Sci. 67, 199-203.

Kachanosky, R.G., 1993. Estimating soil loss from changes in soil cesium-137. Can. J. Soil Sci. 73, 515-526.

Livens, F.R., Rimmer, D.L., 1988. Physico-chemical controls on artificial radionuclides in soil. Soil Use Manage. 4, 63-69.

Lowrance, R., McIntyre, S., Lance, C., 1988. Erosion and deposition in a field/forest system estimated using cesium-137 activity. J. Soil Water Conserv. 43, 195-199.

Martz, L.W., De Jong, E., 1987. Using Cesium-137 to assess the variability of net soil erosion and its association with topography in a Canadian Prairie landscape. Catena 14, 439-451. 
Meehl, G.A., Washington, W.M., Collins, W.D., Arblaster, J.M., Hu, A., Buja, L.E., Strand, W.G., Teng, H. 2005. How much more global warming and sea level rise. Science, 307: 1769-1772.

Navas, A. \& Walling, D. 1992. Using caesium-137 to assess sediment movement in a semiarid upland environment in Spain. In: Erosion, Debris Flows and Environment in Mountain Regions (Walling, D.E., Davies, T.R. \& Hasholt, B. eds.) IAHS Publ. nº 209, 129-138.

Navas, A., Soto, J., Machín, J., 2002a. ${ }^{238} \mathrm{U},{ }^{226} \mathrm{Ra},{ }^{210} \mathrm{~Pb},{ }^{232} \mathrm{Th}$ and ${ }^{40} \mathrm{~K}$ activities in soil profiles of the Flysch sector (Central Spanish Pyrenees). Appl. Radiat. and Isotopes 57, 579-589.

Navas, A., Soto, J., Machín, J., 2002b. Edaphic and physiographic factors affecting natural gamma emiting radionuclide distribution in soils of the Arnás basin (Central Spanish Pyrenees). Eur. J. Soil Sci. 53, 629-638.

Navas, A., García-Ruiz, J.M., Machín, J., Lasanta, T., Walling, D., Quine, T. \& Valero, B. 1997. Aspects of soil erosion in dry farming land in two changing environments of the central Ebro valley, Spain. In: Human Impact on Erosion and Sedimentation (Walling, D.E. \& Probst, J.L. Eds.) IAHS Publi. nº 245: 13-20.

Navas, A., Machín, J., Soto, J., 2005a. Assessing soil erosion in a Pyrenean mountain catchment using GIS and fallout ${ }^{137} \mathrm{Cs}$. Ag. Ecosyst. Environ. 105, 493-506.

Navas, A., Machín, J., Soto, J., 2005b. Mobility of natural radionuclides and selected major and trace elements along a soil toposequence in the central Spanish Pyrenees. Soil Sci. 170 ( 9) 743-757.

Navas, A., Walling, D., Quine, T., Machín, J., Soto, J. 2005c. Soil redistribution patterns and factors along a transect in central Ebro basin (NE Spain) and its 
controls. In: Sediment Budgets 1 (Walling, D.E. \& Horowitz, A.J. Eds.) IAHS Publi. no 291: 70- 77

Navas, A., Walling, D.E., Quine, T., Machín, J., Soto, J., Domenech, S., López-Vicente, M. 2007. Variability in ${ }^{137} \mathrm{Cs}$ inventories and potential climatic and lithological controls in central Ebro valley, Spain. Journal of Radioanalytical and Nuclear Chemistry, 274 (2), 331-339.

Owens, P.N., Walling, D.E. 1998. The use of a numerical mass-balance model to estimate rates of soil redistribution on uncultivated land from ${ }^{137} \mathrm{Cs}$ measurements. J. Environ. Radioactiv. 40(2):185-203.

Poesen, J., van Wesemael, B., Govers, G., Martinez-Fernandez, J., Desmet, P., Vandaele, K., Quine, T., Degraer, G. 1997. Patterns elf rock fragment cover generated by tillage erosion. Geomorphology 18, 183-197.

Quindós, L, Fernández, P., Soto, J., Ródenas, C., Gómez, J., 1994. Radioactivity in Spanish soils. Health Phys. 66, 194-200.

Quine, T. 1989. Use of a simple model to estimate rates of soil erosion from caesium137 data. J. Water Res. 8:54-81.

Quine, T., Navas, A., Walling, D.E., Machín, J., 1994. Soil erosion and redistribution on cultivated and uncultivated land near Las Bardenas in the Central Ebro River Basin, Spain. Land Degrad. Rehabil. 5, 41-55.

Remondo, J., Soto, J., González_Díez, A., Díaz de Terán, J.R., Cendrero, A., 2005. Human impact on geomorphic processes and hazards in mountain areas in northern Spain. Geomorphol. 66, 69-84.

Ritchie, J.C., McHenry, J.R. 1990. Application of radioactive fallout cesium-137 for measuring soil erosion and sediment accumulation rates and patterns: a review. J. Environ. Qual. 19:215-233. 
Sadiki, A., Faleh, A., Navas, A., Bouhlassa, S., 2007. Assessing soil erosion and control factors by the radiometric technique in the Boussouab catchment, Eastern Rif, Morocco. Catena (in press).

Schoorl, J.M., Boix Fayos, C., de Meijer, R.J., van der Graaf, E.R., Veldkamp, A., 2004. The Cs-137 technique applied to steep Mediterranean slopes (Part I): the effects of lithology. Catena.57, 15-34.

Soto, J., Navas, A., 2004. A model of ${ }^{137}$ Cs activity profile for soil erosion studies in uncultivated soils of Mediterranean environments. J. Arid Environ. 59, 719-730.

Wallbrink, P.J., Murray, A.S. 1996. Measuring soil loss using the inventory ratio of ${ }^{210}$ Pbex to ${ }^{137}$ Cs. Soil Sci. Soc. Am. J. 60(4):1201-1208.

Walling, D.E., He, Q., 1998. Use of fallout ${ }^{137}$ Cs measurements for validating and calibrating soil erosion and sediment delivery models. In: Modelling Soil Erosion, Sediment Transport and Closely Related Hydrological Processes, IAHS Publi. $249,267-278$.

Walling, D.E., He, Q., 1999. Improved models for estimating soil erosion rates from cesium-137 measurements. J. Environ. Qual. 28, 6 - 22.

Walling, D.E, Quine, T.A., 1990. Calibration of caesium-137 measurements to provide quantitative erosion rate data. Land Degrad.Rehabil. 2, 161-175.

Walling, D.E., Quine, T.A., 1991. The use of caesium 137 to investigate soil erosion on arable field in the U.K. - potential applications and limitations. J. Soil Sci. 42, 147-165.

Zhang, X., Higgitt, D.L., Walling, D.E., 1990. A preliminary assessment of the potential for using caesium-137 to estimate rates of soil erosion in the Loess Plateau of China. Hydrolog. Sci. J. 35, 267-276. 
Zhang, X., D.E. Walling, He, Q. 1999. Simplified mass balance models for assessing soil erosion rates on cultivated land using caesium-137 measurements. Hydrolog. Sci. 44(1):33-46. 


\section{Tables}

1. Mean values of main soil properties in the studied sites of the South Pyrenean slopes in the Province of Huesca (NE-Spain).

2. Values of the input parameters for the model; measured (exp) and simulated (mod)

${ }^{137}$ Cs concentrations (C) and inventories (I) and rates of erosion (E) estimated at the 11 eroding sites.

3. Values of the input parameters for the model; measured (exp) and simulated (mod) ${ }^{137} \mathrm{Cs}$ concentrations (C) and inventories (I) and rates of deposition (F) estimated at the 5 aggrading sites. 


\section{Figures}

1. Representative profiles of the ${ }^{137} \mathrm{Cs}$ depth distribution at stable, eroded and deposition sites along slopes in the study area (Carrodilla Range, South Pyrenees)

2. Measured (exp) and simulated (mod) ${ }^{137} \mathrm{Cs}$ profiles at representative eroding sites in the slope transects studied.

3. Measured (exp) and simulated (mod) ${ }^{137} \mathrm{Cs}$ profiles at representative deposition sites in the slope transects studied. 
Table 1. Mean values of main soil properties in the studied sites of the South Pyrenean slopes in the Province of Huesca (NE-Spain).

\begin{tabular}{|c|c|c|c|c|c|c|c|c|c|c|c|}
\hline \multirow[t]{2}{*}{ Site } & Depth & $\begin{array}{r}\text { Stoniness } \\
>2 \mathrm{~mm}\end{array}$ & Bulk density & $\mathrm{pH} \mathrm{H}_{2} \mathrm{O}$ & EC & $\mathrm{CO}_{3}{ }^{2-}$ & TOC & $\mathbf{O M}$ & Sand & Silt & Clay \\
\hline & $\mathbf{c m}$ & $\%$ & $\mathrm{~g} \mathrm{~cm}^{-3}$ & $(1: 2.5)$ & $\mathrm{dSm}^{-1}$ & $\%$ & $\%$ & $\%$ & $\%$ & $\%$ & $\%$ \\
\hline E-1 & 35 & 30.0 & 1.51 & 8.25 & 0.287 & 37.4 & 0.74 & 1.3 & 11.3 & 67.8 & 20.9 \\
\hline E-2 & 37 & 44.7 & 1.50 & 8.43 & 0.175 & 35.3 & 0.88 & 1.5 & 20.6 & 58.9 & 20.5 \\
\hline E-4 & 35 & 44.9 & 1.36 & 8.06 & 0.208 & 34.2 & 1.54 & 2.6 & 24.9 & 59.3 & 15.8 \\
\hline W-7 & 47 & 18.4 & 1.53 & 8.29 & 0.197 & 29.4 & 1.02 & 1.8 & 13.9 & 63.9 & 22.2 \\
\hline W-6 & 41 & 32.7 & 1.44 & 8.37 & 0.159 & 37.3 & 0.88 & 1.5 & 15.0 & 65.5 & 19.4 \\
\hline W-4 & 47 & 23.2 & 1.56 & 8.55 & 0.149 & 36.6 & 1.15 & 2.0 & 7.5 & 69.4 & 23.1 \\
\hline W-5 & 40 & 59.5 & 1.99 & 8.66 & 0.127 & 53.4 & 0.58 & 1.0 & 8.7 & 71.9 & 19.4 \\
\hline W-11 & 47 & 21.9 & 1.54 & 8.39 & 0.177 & 48.0 & 0.68 & 1.2 & 5.2 & 72.2 & 22.6 \\
\hline W-12 & 35 & 26.5 & 2.27 & 8.76 & 0.107 & 85.8 & 1.04 & 1.8 & 2.4 & 77.5 & 20.2 \\
\hline S-12 & 30 & 55.1 & 2.05 & 8.47 & 0.206 & 45.2 & 2.58 & 4.4 & 1.8 & 73.7 & 24.5 \\
\hline S-14 & 47 & 34.8 & 1.40 & 8.54 & 0.180 & 49.9 & 0.75 & 1.3 & 0.6 & 68.6 & 30.7 \\
\hline S-15 & 43 & 13.8 & 1.44 & 8.45 & 0.174 & 18.6 & 1.23 & 2.1 & 0.4 & 68.3 & 31.3 \\
\hline S-20 & 45 & 15.4 & 1.62 & 8.20 & 0.477 & 45.5 & 0.93 & 1.6 & 2.0 & 77.6 & 20.4 \\
\hline S-21 & 40 & 21.7 & 2.05 & 7.94 & 2.313 & 20.9 & 0.62 & 1.1 & 1.1 & 61.5 & 37.4 \\
\hline S-22 & 53 & 16.0 & 1.66 & 7.96 & 2.321 & 19.9 & 0.71 & 1.2 & 10.0 & 64.7 & 25.2 \\
\hline $\mathrm{S}-23$ & 55 & 5.1 & 1.43 & 7.95 & 2.582 & 15.6 & 0.96 & 1.7 & 0.5 & 73.5 & 26.1 \\
\hline
\end{tabular}



Table 2. Values of the input parameters for the model; measured (exp) and simulated (mod) and ${ }^{137}$ Cs concentrations (C) and inventories (I) and rates of erosion (E) estimated at the 11 eroding sites.

\begin{tabular}{|c|c|c|c|c|c|c|c|}
\hline site & $\mathbf{V}_{\mathbf{f}}$ & $\begin{array}{c}\mathbf{H} \\
\mathbf{c m}\end{array}$ & $\begin{array}{c}{ }^{137} \mathrm{Cs} \\
\mathrm{C} \\
\mathrm{mBq}^{-1}\end{array}$ & $\begin{array}{c}{ }^{137} \mathrm{Cs} \\
\mathrm{I} \\
\mathrm{mBq} \mathrm{cm}^{-2}\end{array}$ & $\begin{array}{l}\text { Density } \\
<2 \mathrm{~mm}^{-3} \\
\mathrm{~g} \mathrm{~cm}^{-3}\end{array}$ & $\begin{array}{c}E \\
\text { cm month }\end{array}$ & $\begin{array}{c}\mathrm{E} \\
\operatorname{Mg~ha}^{-1} \mathrm{yr}^{-1}\end{array}$ \\
\hline E-2 exp & 0.73 & 25 & 4.4 & 103.2 & 0.94 & & \\
\hline E-2 mod & & & 4.4 & 103.2 & & 0.016 & 18.0 \\
\hline W-4 exp & 0.74 & 35 & 4.7 & 112.1 & 0.68 & & \\
\hline W-4 mod & & & 4.7 & 112.4 & & 0.018 & 14.7 \\
\hline W-4 exp & 0.86 & 25 & 3.6 & 102.3 & 1.14 & & \\
\hline W-4 mod & & & 3.6 & 102.7 & & 0.019 & 26.0 \\
\hline W- $5 \exp$ & 0.54 & 25 & 2.8 & 68.3 & 0.97 & & \\
\hline W $5 \bmod$ & & & 2.8 & 68.2 & & 0.0235 & 27.3 \\
\hline W- $6 \exp$ & 0.81 & 35 & 3.2 & 102.2 & 0.90 & & \\
\hline W-6 mod & & & 3.2 & 102.8 & & 0.025 & 27.0 \\
\hline W-11 exp & 0.86 & 25 & 4.2 & 98.0 & 0.93 & & \\
\hline W-11 mod & & & 4.2 & 98.2 & & 0.021 & 23.4 \\
\hline W- $12 \exp$ & 0.77 & 15 & 1.4 & 32.2 & 1.50 & & \\
\hline $\mathrm{W}-12 \bmod$ & & & 1.4 & 32.1 & & 0.0385 & 69.3 \\
\hline S- $12 \exp$ & 0.56 & 15 & 5.0 & 83.0 & 1.11 & & \\
\hline $\mathrm{S}-12 \mathrm{mod}$ & & & 5.1 & 83.8 & & 0.011 & 14.6 \\
\hline S- $14 \exp$ & 0.81 & 20 & 5.5 & 107.0 & 0.97 & & \\
\hline $\mathrm{S}-14 \bmod$ & & & 5.5 & 106.8 & & 0.013 & 15.1 \\
\hline$S-15 \exp$ & 0.92 & 40 & 2.2 & 123.0 & 1.40 & & \\
\hline $\mathrm{S}-15 \mathrm{mod}$ & & & 2.2 & 123.5 & & 0.019 & 31.9 \\
\hline S- $22 \exp$ & 0.90 & 30 & 3.0 & 128.9 & 1.43 & & \\
\hline$S-22 \bmod$ & & & 3.0 & 129.1 & & 0.010 & 17.2 \\
\hline
\end{tabular}



Table 3. Values of the input parameters for the model; measured (exp) and simulated (mod) and ${ }^{137} \mathrm{Cs}$ concentrations (C) and inventories (I) and rates of deposition (F) estimated at the 5 deposition sites.

\begin{tabular}{|c|c|c|c|c|c|c|c|}
\hline Site & $\mathbf{V}_{\mathbf{f}}$ & $\begin{array}{l}\mathrm{H} \\
\mathrm{cm}\end{array}$ & $\begin{array}{c}{ }^{137} \mathrm{Cs} \\
\mathrm{mBq} \mathrm{g}^{-1}\end{array}$ & $\begin{array}{c}\quad{ }^{137} \mathrm{Cs} \\
\text { inventory } \\
\mathrm{mBq} \mathbf{~ c m}^{-2}\end{array}$ & $\begin{array}{l}\text { Density } \\
<2 \mathrm{~mm} \\
\mathrm{~g} \mathrm{~cm}^{-3}\end{array}$ & $\begin{array}{c}\text { F } \\
\text { cm month }^{-1}\end{array}$ & $\begin{array}{c}\mathrm{F} \\
\mathrm{Mg} \mathrm{ha}^{-1} \mathrm{yr}^{-1}\end{array}$ \\
\hline E- $1 \exp$ & 0.81 & 35 & 3.8 & 158.8 & 1.25 & & \\
\hline E -1 mod & & & 3.8 & 158.7 & & 0.0006 & 0.9 \\
\hline W-7 exp & 0.89 & 40 & 4.6 & 216.7 & 1.18 & & \\
\hline W-7 mod & & & 4.6 & 216.4 & & 0.0236 & 33.4 \\
\hline$S-20 \exp$ & 0.90 & 30 & 4.8 & 203.7 & 1.41 & & \\
\hline$S-20 \bmod$ & & & 4.8 & 203.6 & & 0.0145 & 24.5 \\
\hline S- $21 \exp$ & 0.82 & 25 & 4.3 & 171.6 & 1.60 & & \\
\hline S -21 mod & & & 4.2 & 171.4 & & 0.0037 & 7.1 \\
\hline S- $23 \exp$ & 0.97 & 30 & 4.0 & 183.7 & 1.53 & & \\
\hline$S-23 \bmod$ & & & 4.0 & 183.6 & & 0.0094 & 17.3 \\
\hline
\end{tabular}




\section{${ }^{137} \mathrm{Cs} \mathrm{Bq} \mathrm{kg}^{-1}$}
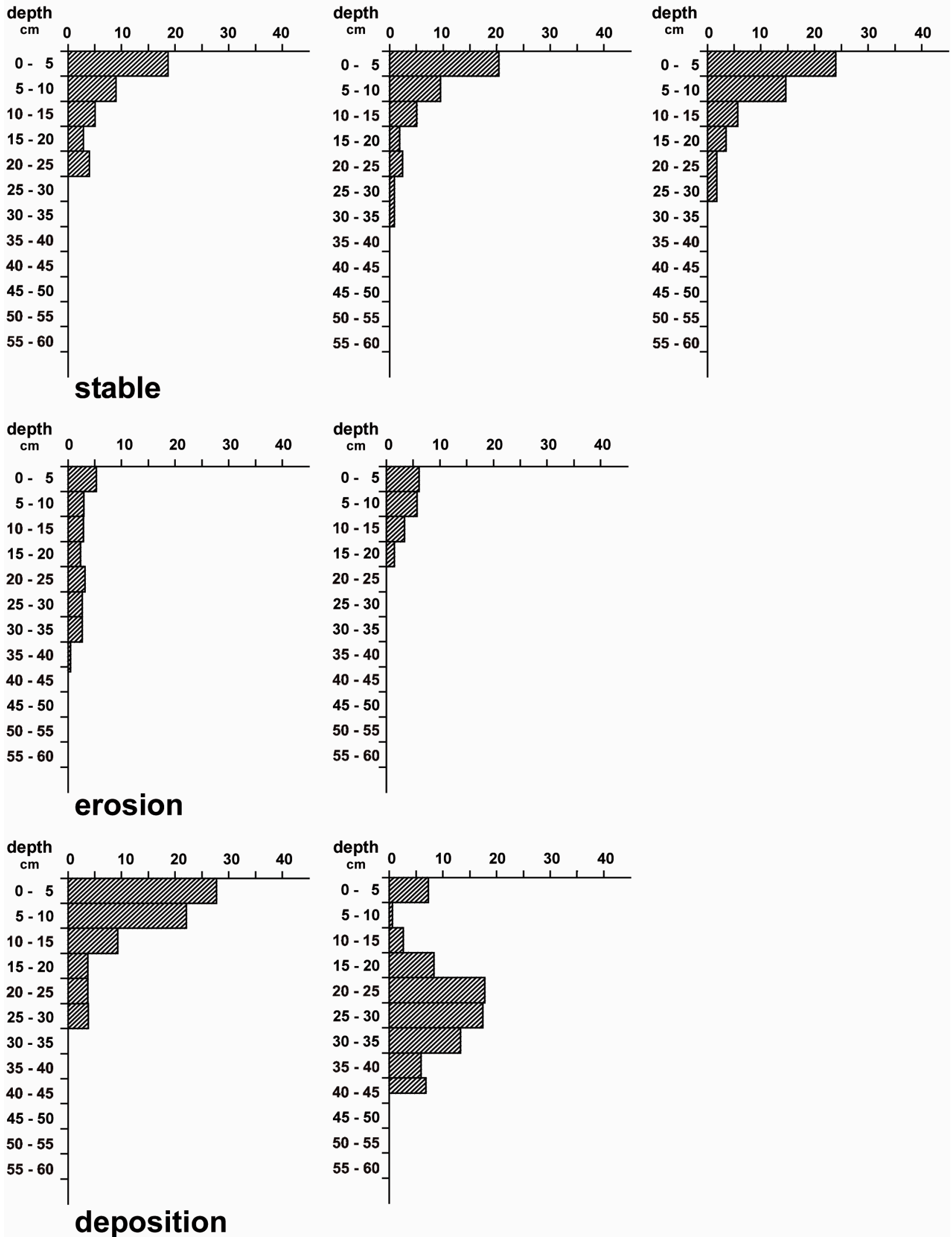

Figure 1 


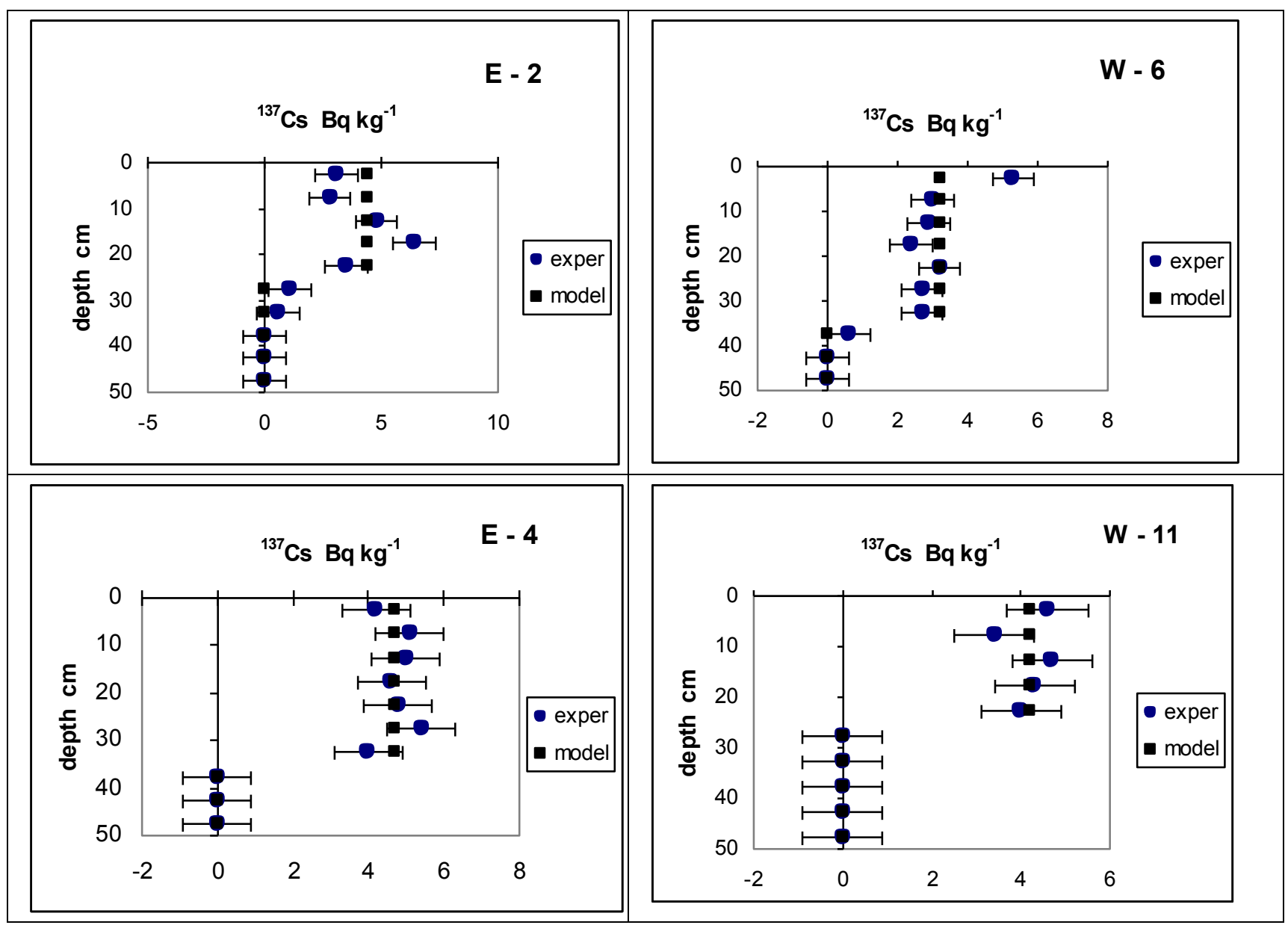

Figure 2 


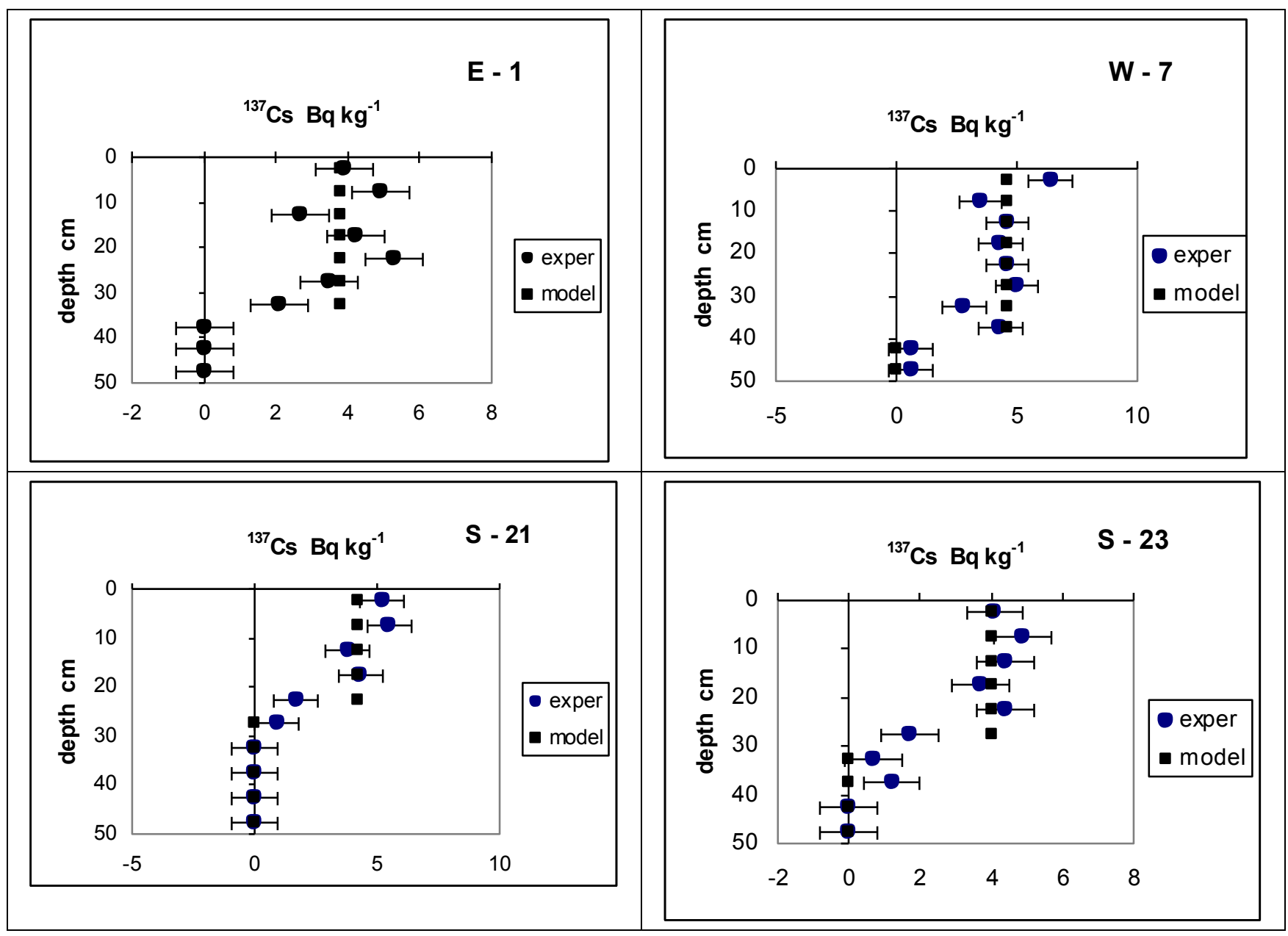

Figure 3 